\title{
LAYOUT EM NOVOS EMPREENDIMENTOS: ESTUDO DE CASO DE UMA
} PROCESSADORA DE CAFÉS ESPECIAIS

\section{NEW FACTORY LAYOUT: CASE STUDY ON A SPECIAL COFFEE PROCESSOR}

\section{Elisângela Aparecida dos Santos Mesquita, Gabrielle Batalini dos Santos, Thomas Henrique Alves da Cruz, Rafael Medeiros Hespanhol}

Universidade do Oeste Paulista - UNOESTE, Faculdade de Engenharia, Curso de Engenharia de Produção, Presidente Prudente, SP.

E-mail: lissmesquita@gmail.com

RESUMO - Desenvolvimento do layout de produção é um dos principais pontos para a criação de um novo empreendimento, independente do seu segmento. $O$ presente trabalho tem como objetivo principal o desenvolvimento de um layout de fábrica para o processamento de café do tipo arábica. Foram considerados dados quantitativos e qualitativo por meio do método PSL (Planejamento Sistemático de Layout), para tanto foram realizados estudos sobre os equipamentos necessários, suas dimensões e capacidades produtivas, baseando-se nos seis princípios da otimização de layout. O resultado apresentou uma proposta de layout, com a disposição dos equipamentos seguindo o princípio de arranjo por produto. Foi ainda elaborado a confecção das plantas baixas da fábrica como um todo, e a explicação do fluxo de processamento.

Palavras-chave: Layout, processamento de café, café arábica, Projeto de Fábrica.

ABSTRACT - The process of develop a production layout is one of the key aspects of creating a new company, regardless of its market segment. This study aims to develop a facility layout for arabica coffee processing. Quantitative and qualitative data were analyzed through the SLP (Systematic Layout Planning) method, for this purpose, a research of the necessary equipment was developed, regarding its dimensions and production capacity. Was also considered the six principles of layout optimization. The result was a layout proposal, with an array of equipment following the principle of arrangement by processes. It was also elaborated the facility plant, with the explanation of the process flow.

Keywords: Layout, Coffee processing, Arabica Coffee, Plant Layout. 


\section{INTRODUÇÃO}

Um fator que pode afetar significativamente no aumento da produtividade nas organizações é o arranjo físico das instalações industriais, também conhecido como Plant Layout. Um layout envolve além da preocupação de melhor adaptar as pessoas ao ambiente de trabalho, englobando critérios de adequação dos postos de trabalho em espaços disponíveis, seguindo o fluxo de atividades a serem desempenhadas, arrumação dos móveis, equipamentos e matérias-primas, de acordo com Llatas.

A revisão ou a implantação de um layout é fundamental, por compreender o estudo sobre a disposição de todas as áreas da empresa, segundo Oliveira (2011) o correto dimensionamento do layout proporciona um fluxo mais eficiente e eficaz de comunicações entre os setores organizacionais, além de garantir a melhor utilização das áreas disponíveis na empresa. Além disso, um bom layout assegura melhor desempenho produtivo devido ao ambiente ajustado de acordo com as necessidades do seu processo e de seus colaboradores, tornando-os mais eficientes, conforme seu modo de organização, além de minimizar custos operacionais evitando movimentações e fluxos desnecessários.

A análise do presente trabalho irá explorar uma nova oportunidade de negócio em bens de consumo não duráveis de café. A fábrica de produção de café será situada no município de Martinópolis - SP, onde será realizado um estudo a fim de implantar o layout mais adequado para sua instalação industrial, com o objetivo de aplicar os métodos de organização necessários, buscando estabelecer a melhor combinação entre máquinas e fluxos de processos, visando um ambiente moderno e capaz de atender as necessidades do processo de fabricação do café, além de proporcionar uma maior interação e cooperação entre os colaboradores.

\section{METODOLOGIA}

O presente estudo foi realizado na Universidade do Oeste Paulista, UNOESTE, Campus II de Presidente Prudente - SP, entre os meses de abril e maio do ano de 2018, e a metodologia utilizada para desenvolver essa pesquisa é classificada como qualitativa, quantitativa, bibliográfica e explicativa, em que o intuito foi identificar o Plant Layout mais eficiente e harmonioso para o processo de manufatura do café, visando a melhor utilização dos recursos disponíveis em uma empresa, denominada no presente trabalho de Empresa $\mathrm{X}$.

Para a aplicação da melhor metodologia para o Plant Layout da Empresa X, foi necessário identificar e compreender itens como, o processo de manufatura do café para então conseguir alocar e integrar equipamentos, mão de obra, movimentação, estocagem, administração, mão de obra indireta; dentro de um espaço disponível, de acordo com Oliverio (1985).

Basseto (et al, 2016) explica que o processo de transformação da commodity café em bem de consumo, é relativamente simples, composto por etapas de recepção e análise dos grãos, torrefação, moagem, embalagem, rotulagem, armazenamento e entrega do produto ao cliente. Apesar de ser o início de um novo empreendimento para a Empresa $\mathrm{X}$, o setor econômico em bem de consumo não durável de café já é existente e bem consolidado no mercado mundial, o que traz a estruturação do layout uma maior facilidade, tornando-se então, apenas uma adequação as necessidades que a empresa apresenta.

No presente estudo, será identificado o arranjo físico ideal para a Empresa $X$, adequandoo ao processo de manufatura do café por meio do posicionamento de equipamentos e mão de obra e atentando-se em fatores de eficiência não só dos equipamentos, mas também no que o ambiente proporcionara na melhor produtividade da mão de obra, com aspectos de ventilação, iluminação, climatização, movimentação, entre outros.

\section{CONCEITOS DE ARRANJO FÍSICO}

O arranjo físico de uma operação produtiva preocupa-se com o posicionamento físico dos recursos de transformação, já que o mesmo pode afetar diretamente a produtividade da organização.

O planejamento de um layout torna o projeto mais particular possível, por mais que existem layouts para o mesmo setor industrial, cada empresa tem suas particularidades e necessidades, tornando-se exclusivo. Balancear aspectos como conceitos de qualidade, restrições financeiras e recursos do meio ambiente é um dos grandes desafios do projeto. Para isso, Luzzi (et al, 2004) salientam quatro formas de 
planejamento de layout: baseando-se na experiência (especialistas de diversas áreas interagem com a proposta de desenvolvimento do projeto, com base na sua experiência e criatividade); algoritmos computacionais (dividido em métodos de melhoramentos e de construção; onde o melhoramento parte de um layout inicial e o de construção parte de um esboço que cada estação de trabalho é alocada, gerando somente uma solução, pode-se haver situações que encontram-se os dois métodos); planejamento sistemático de layout (PSL) (incorpora aspectos qualitativos e quantitativos, dividindo-se o projeto em várias etapas sequenciais, por meio de alternativas geradas para as necessidades do projeto); planejamentos integrais de layout (visa a eficiência de trabalho e a qualidade de vida no trabalho, enfatizando a estrutura organizacional).

Segundo Oliverio (1985), existem seis princípios importantes que devem ser analisados e seguidos para planejar um arranjo físico, sendo eles: o princípio da mínima distancia (reduzir a distância percorrida); o princípio de obediência ao fluxo de operações (movimento ininterrupto de acordo com a sequência de manufatura); o princípio da flexibilidade (a possibilidade adaptar o arranjo às mudanças); o princípio da integração (a integração entre diversos elementos é necessária para que o arranjo físico seja ótimo); o princípio do uso das três dimensões (a utilizações do espaço no quesito volume); o princípio da satisfação e segurança (proporcionar boas condições de trabalho e minimizar riscos).

Na prática a maioria dos arranjos físicos provém de quatro tipos básicos, que são: arranjo físico posicional ou posição fixa (a manufatura permanece estacionária, havendo fluxo apenas de equipamentos, maquinários, instalações e pessoas); arranjo físico processo, funcional ou departamental (operações similares são agrupadas em um mesmo local ou departamento); arranjo físico por produto ou linear (obedece a sequência do processamento do produto, onde todas as máquinas e os processos necessários são agrupados juntos e sequenciais); arranjo físico celular (composto de células de produção e montagem interligadas, onde operações e processos são agrupados de acordo com a sequência de produção que é necessária para fazer um grupo de produtos) (SLACK, 2009).

Dessa forma, pode-se dizer que arranjo físico está ligado a estratégia funcional da empresa. O layout proporciona ao ambiente fabril a minimização de perdas por meio da melhor utilização do espaço disponível, com redução de horas-homem em transporte; melhoria de índices de qualidade; redução do lead-time produtivo; aumento da produtividade; comprometimento dos funcionários.

\section{RESULTADOS}

A proposta da região de instalação da Empresa $X$, foi demandada com base em alguns critérios, como: oferta de matéria prima; público alvo; custos de mão de obra; leis e impostos; energia; transporte; serviços de água e comunicação; entre outros. A partir desses critérios, a instalação da fábrica foi direcionada para o Oeste Paulista. O município de escolha foi Martinópolis - SP e o lugar de instalação será na Via José Biazini, considerada distrito industrial (subúrbio) do município. O terreno apresenta dimensões de 100 metros de frente e 150 metros de fundo, totalizando 15.000 metros quadrados.

Com base no processo de transformação da commodity café em bem de consumo não durável, o fluxograma foi desenvolvido e apresentou as características da Figura 1. 
Figura 1. Fluxograma do processo produtivo do café

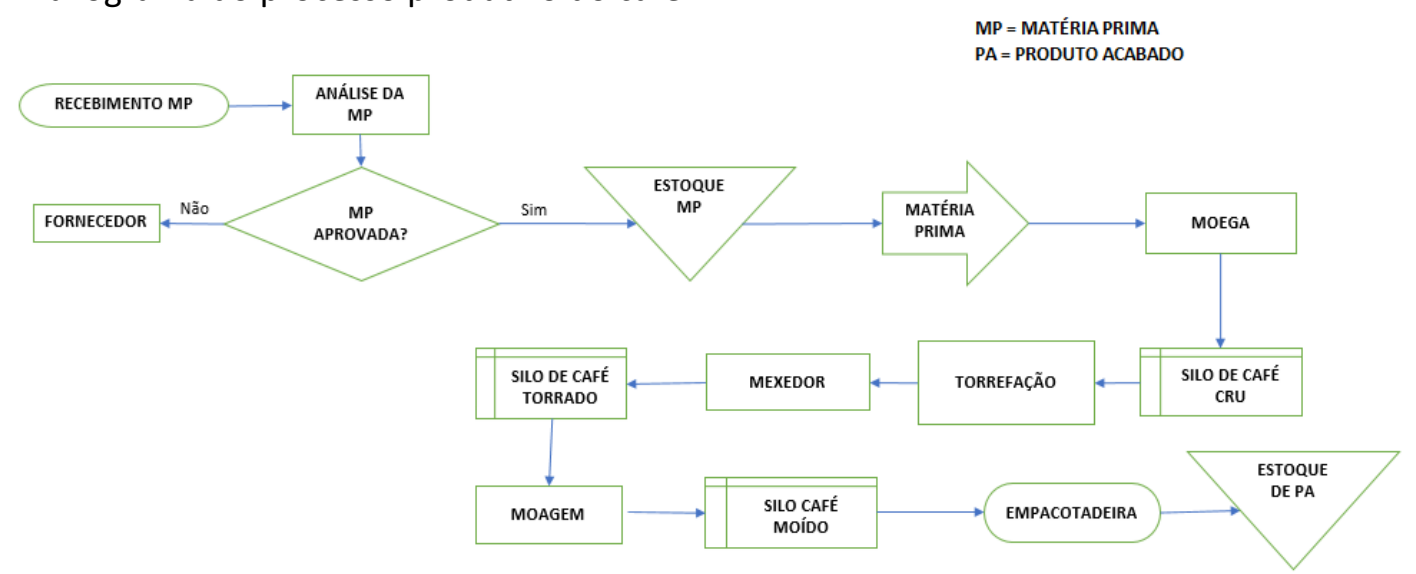

Fonte: Elaborado pelos autores

A partir das dimensões do terreno, as necessidades apresentadas pelo fluxograma e com base nas teorias citadas no presente artigo, o layout proposto foi desenvolvido com o auxílio do software AutoCad, conforme a Figura 2 e em seguida, no Quadro 1, apresenta a legenda que refere-se aos equipamentos disponíveis na fábrica da Empresa $X$, para atender as necessidades da mesma.

Figura 2. Processamento e armazenamento do café

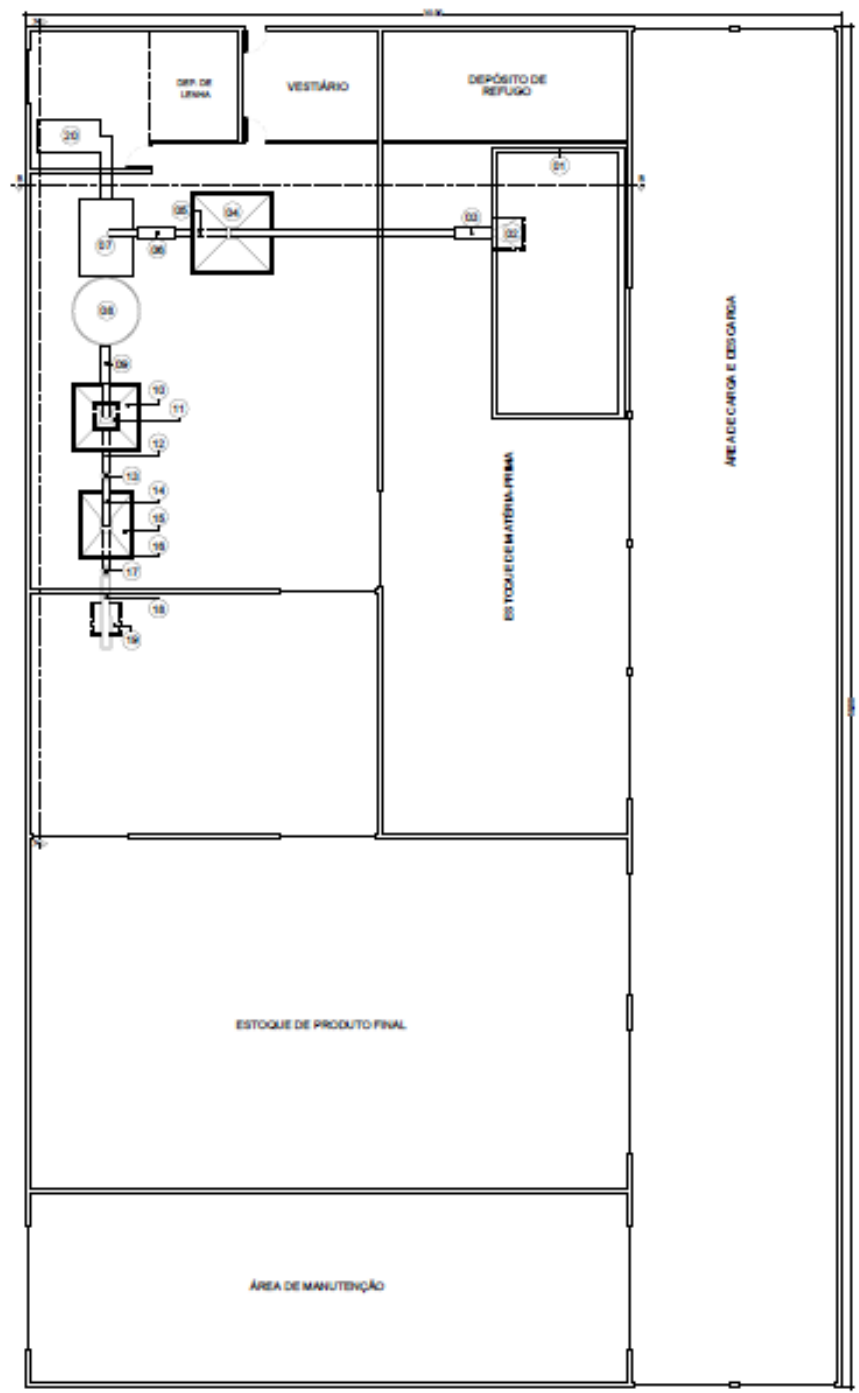

Fonte: Elaborado pelos autores 
Quadro 1. Legenda da planta 2D

\begin{tabular}{|l|l|c|l|}
\hline 1 & Ponte rolante & 11 & Moinho \\
\hline 2 & Moega & 12 & Rosca transportadora (2) \\
\hline 3 & Elevador de caneca (1) & 13 & Elevador de rosca \\
\hline 4 & Silo para grãos (1) & 14 & Rosca transportadora (3) \\
\hline 5 & Rosca transportadora (1) & 15 & Silo p/ café moído \\
\hline 6 & Elevador de caneca (2) & 16 & Rosca transportadora (4) \\
\hline 7 & Torrador & 17 & Elevador de rosca (2) \\
\hline 8 & Mexedor & 18 & Arrastador p/ pó \\
\hline 9 & Elevador de caneca (3) & 19 & Empacotadeira \\
\hline 10 & Silo p/ grãos torrados & 20 & Fornalha \\
\hline
\end{tabular}

Fonte: Elaborado pelos autores

O processo produtivo do café segue um fluxo contínuo, pensando nesse aspecto, a melhor forma de organizar a disposição dos equipamentos, foi o de fluxo linear. A planta desenvolvida foi criada para uma única finalidade, o processamento e empacotamento de café em pó, processo esse que não demanda variações da disposição, quando se tem um fluxo contínuo de produção. Dessa forma o layout proposto para o processamento do café, foi desenvolvido com a visão focada e seguindo as definições do layout por produto.

As facilidades do escritório, se assemelham com as características do arranjo por processo, onde no escritório cada pessoa está desempenhando uma função alocada em uma mesa, sendo o trabalho designado a ela, sem a necessidade de seguir um fluxo determinado que não possa sofrer variação, ou seja, é baseado na demanda de trabalho e dentro do prédio do escritório, foi alocado funções similares. Dentro do laboratório, os equipamentos foram dispostos em lugares fixos, sendo que podem atender a demanda de análises solicitadas e a lógica da alocação do laboratório nessa área do terreno, demanda aspectos do arranjo celular, onde o laboratório é um setor de análise de inputs e outputs do processo produtivo, havendo necessidades de aspectos como o fácil acesso de entrada e saída de caminhões.

Para a obtenção do melhor desempenho em nível de produtividade, da redução de desperdícios e do controle do processo, os seis princípios do desenvolvimento de layout foram utilizados, o primeiro deles, foi o princípio da mínima distância, que para elaboração da planta, foram analisados os espaços mínimos necessários para operação, higienização e manutenção dos equipamentos, respeitando as dimensões de cada máquina; após feita essa análise, a menor distância possível para alocação do próximo equipamento foi tomada como estratégia. Seguindo a mesma linha estratégica, o princípio de obediência ao fluxo de operações se dá, pela disposição contínua dos equipamentos, pois não há fluxo contrário, a matéria prima é transformada durante o processo, sem a necessidade de retomar a nenhuma operação.

O princípio da flexibilidade foi tomado nos aspectos ao que se refere à mudança de arranjo para variação do fluxo de demanda da produção, para tanto, existem espaços que podem ser utilizados para ampliação da linha produtiva, caso seja necessário, a inclusão de novos equipamentos para suprir a insuficiência produtiva quando ocorrer um aumento na demanda.

Para que o arranjo físico seja considerado como ótimo, é necessário adotar o princípio da integração, pensando nisso, o fluxo produtivo é interligado por meio de equipamentos de transporte, sendo os principais como elevadores de caneca e as roscas transportadoras, assim, ao finalizar a fase atual do processo, a matéria prima é transportada para a próxima fase, de maneira autônoma e seguindo um fluxo pré-determinado.

Foi também respeitado o princípio de utilização das três dimensões, para as fases de armazenamento em silos, o transporte é feito de maneira totalmente horizontal, por meio de elevadores de caneca, o que ocupa menos espaço na disposição dos equipamentos. Ainda foi levado em conta, a disposição dos silos na parte superior dos equipamentos posteriores no processo, como por exemplo, a disposição do silo na parte superior do moinho.

O princípio de satisfação e segurança foi respeitado, pelo estudo das normas de disposição 
de equipamentos, respeitando o espaçamento necessário para a operação dos equipamentos, com foco na segurança e na fluidez das operações.

\section{CONSIDERAÇÕES FINAIS}

O presente trabalho teve como principal objetivo a criação de um layout para o processamento de café, para tanto, foi utilizado as características do arranjo físico baseado em produto, e os seis princípios para otimização do layout. Como resultado obtiveram-se os desenhos das disposições do fluxo, a escolha do terreno, e também a disposição do escritório, do laboratório e das áreas de carga e descarga de matéria prima e produtos finalizados.

Como principais limitações ao trabalho, foi encontrada a dificuldade de desenvolvimento das disposições dos equipamentos no formato 3D, sendo apresentados somente em 2D. Também não foram considerados os aspectos de segurança dos equipamentos em relação ao nível de ruído apresentado e a quantidade de poluentes que pode afetar o meio ambiente e a segurança do trabalhador.

Para possíveis estudos relacionados ao tema, os campos de aplicação de melhoria por meio de metodologias como o PDCA e o 5S poderiam trazer melhorias consideráveis ao processo, em relação à organização e busca de soluções para facilidades com espaços limitados. Também se torna interessante 0 estudo detalhado do possível balanço das operações oriundas desse tipo de layout, levando em consideração os equipamentos e a capacidade de produção total da fábrica.

\section{REFERÊNCIAS}

AMARAL, L. et al. O papel do arranjo físico e da gestão de informações como ferramenta para melhoria da competitividade e desempenho dos processos de uma lavanderia industrial / The role of physical arrangement and management information as a tool for improving comp. Revista Metropolitana de Sustentabilidade (ISSN 2318-3233), [S.I.], v. 2, n. 2, p. 48-63, mar. 2015. ISSN 2318-3233. Disponível em: $<$ http://revistaseletronicas.fmu.br/index.php/rms /article/view/193>. Acesso em: 11 maio 2018.

BASSETO, P.; ESPIRITO SANTO, R. S. Processo Produtivo do café torrado. X EPPA - X Econtro de
Engenharia de Produção Agroindustrial. set. 2016. Disponível em: http://www.fecilcam.br/anais/x eepa/data/uplo ads/11-agroindustria/11-01.pdf. Acesso em: 11 maio 2018.

BRASIL. Ministério do Trabalho. Normas Regulamentadoras. Brasília, 2015. Disponível em: $<$ http://trabalho.gov.br/seguranca-e-saude-notrabalho/normatizacao/normasregulamentadoras>. Acesso em: 12 maio 2018.

LLATAS, M. V. Organização Sistemas e Métodos, uma visão contemporânea. São Paulo: Pearson Prentice Hall, 2011.

LUZZI, A. A. Uma abordagem para projetos de layout industrial em sistemas de produção enxuta: um estudo de caso. 2004. Disponível em: $<$ http://hdl.handle.net/10183/4721 >. Acesso em: 15 maio 2018.

OLIVEIRA, D. P. R. Sistemas, organização e métodos: uma abordagem regencial. 20. ed. São Paulo: Atlas, 2011.

OLIVERIO, J. L. Projeto de Fábrica: produtos, processos e instalações industriais. São Paulo: IBLC, 1985.

SILVA SEGUNDO, S. J.; ARAÚJO, W. J.; LOPES, W. A. Projeto de layout de biblioteca assistido por ferramenta de software para criação de arranjo físico em 3D: estudo aplicado à biblioteca da faculdade iDEZ. Informação \& Informação, [S.I.], v. 18 , n. 1 , p. 184-205, jun. 2013. ISSN 1981-8920. Disponível em: $<$ http://www.uel.br/revistas/uel/index.php/infor macao/article/view/10115>. Acesso em: 11 maio 2018.

SLACK, N.; JOHNSTON, R.; CHAMBERS, S. Administração da produção. Tradução: Luiz Henrique Corrêa. 3. ed. São Paulo: Atlas, 2009.

REZENDE, W. D. et al. Análise e redesenho do layout de processo de uma empresa: estudo de caso em uma indústria têxtil da Zona da Mata, utilizando software Arena. In: SIMPÓSIO DE ENGENHARIA DE PRODUÇÃO DE SERGIPE, 8., 2016, São Cristóvão. Anais eletrônicos... São Cristóvão: DEPRO/UFS, 2016. p. 245-257. Disponível em: <http://simprod.ufs.br/pagina/20298>. Acesso em: 22 abr. 2018. 
TOMELIN, M.; COLMENERO, J. C. Método para definição de layout em sistemas job-shop baseado em dados históricos. Produção, v. 20, n. 2, p. 274-289, 2010. Disponível em: <http://www.ingentaconnect.com/content/doai/ 01036513/2010/00000020/00000002/art00011>. Acesso em: 15 maio 2018.

VAZ, F. J. A. Planejamento sistêmico de layout (PSL): analise em uma fábrica de panela de pressão. 2015. Disponível em: $<$ http://dspace.bc.uepb.edu.br/ispui/handle/123 456789/8067>. Acesso em: 15 maio 2018. 